\title{
GIÁ TRI PHƯƠNG PHÁP CHỤP XQUANG PHỔ HAI MỨC NĂNG LƯỢNG CÓ TIÊM THUỐC CẢN QUANG TRONG CHẨN ĐOÁN UNG THƯ TUYỂN VÚ
}

\author{
Trần Thị Bích Hạnh*, Nguyễn Minh Hải**, Vũ Thu Thủy*, \\ Trần Thị Phương Thảo*, Lê Thị Thanh Xuân*
}

\section{TÓM TẮT}

Mục tiêu: Đánh giá giá trị chẩn đoán ung thư vú của phương pháp chup $X$ quang phổ hai mức năng lượng có tiểm thuốc cản quang (CESM) so với kết quả mồ bệnh họ. Phương pháp: Mô tả cắt ngang, hồi cứu. Kết quả: Nghiên cứu trên 50 bệnh nhân có tổn thương u vú được chụp CESM, độ tuổi trung bình là $49,86 \pm 12,06$. Hình ả̉nh khối đa thùy trên CESM có độ nhạy $71,4 \%$, độ đặc hiệu $68,2 \%$, giá trị dự báo dương tính $74,1 \%$ và giá trị dự báo âm tính $65,2 \%$, độ chính xác $60 \%$. Hình ảnh đường bờ không rỗ nét trên CESM có độ nhạy 53,6\%, độ đặc hiệu 77,3\%, giá trị dự báo dương tính $75 \%$ và giá trị dự báo âm tính $56,7 \%$, độ chính xác $64 \%$. Hình ảnh u xâm lấn trên CESM có độ nhạy 42,9\%, độ đặc hiệu 95,5\%, giá trị dự báo dương tính $92,3 \%$ và giá trị dự báo âm tính $56,8 \%$, độ chính xác $66 \%$. Hình ảnh ngấm thuốc trên CESM có độ nhay $89,3 \%$, đô đăc hiệu $90,9 \%$, giá trị dự báo dương tính $92,6 \%$ và giá trị dự báo âm tính $87 \%$, độ chính xác $90 \%$. Phân loại BIRADS $\geq 4$ trên CESM có độ nhạy 96,4\%, độ đặc hiệu 22,7\%, giá trị dự báo dưởng tính $61,4 \%$ và giá trị dự báo âm tính 83 ,3\%, độ chính xác 64\%. Kết luận: Hình ảnh Chụp XQ tuyến vú phổ hai mức năng lưởng CESM đánh giá hiệu quả những tổn thương tăng đậm độ, thể hiện rõ ràng tính chất khối, ít bỏ sót tổn thương, do đó có giá trị trong việc chẩn đoán ung thư vú với các đối tượng có tuyến vú đâm đăc.

Tư khóa: U vú, X quang phổ hai mức năng lượng có tiêm thuốc cản quang

\section{SUMMARY \\ VALUE OF CONTRAST ENHANCED SPECTRAL MAMMOGRAPHY IN DIAGNOSIS OF BREAST CANCER}

Objectives: To evaluate the diagnostic values of contrast enhanced spectral mammography (CESM) in patient withbreast cancer compared with histopathological results. Methods: Retrospective, cross-sectional study. Results: Studying on 50 patients with breast tumor lesions undergoing CESM, the average age was $49.86 \pm 12.06$. Multi-lobular mass on CESM had a sensitivity of $71.4 \%$, specificity of $68.2 \%$, a positive predictive value of $74.1 \%$ and a negative predictive value of $65.2 \%$, with an accuracy of $60 \%$. The indistinct margin mass on CESM had a

\footnotetext{
*Bệnh viện TWQĐ 108.

**Bênh viện 103, HVQY.

Chịu trách nhiệm chính: Trân Thị Bích Hạnh

Email: nmhaidr@gmail.com

Ngày nhận bài: 12/7/2021

Ngày phản biện khoa học: 10/8/2021

Ngày duyệt bài: 25/8/2021
}

sensitivity of $53.6 \%$, a specificity of $77.3 \%$, a positive predictive value of $75 \%$ and a negative predictive value of $56.7 \%$, with an accuracy of $64 \%$. Invasive tumor on CESM X-ray had a sensitivity of $42.9 \%$, a specificity of $95.5 \%$, a positive predictive value of $92.3 \%$ and a negative predictive value of $56.8 \%$, with an accuracy of $66 \%$. The image of enhancement on CESM had a sensitivity of $89.3 \%$, a specificity of $90.9 \%$, a positive predictive value of $92.6 \%$ and a negative predictive value of $87 \%$, with an accuracy of $90 \%$. The BIRADS classification $\geq 4$ on CESM has a sensitivity of $96.4 \%$, a specificity of $22.7 \%$, a positive predictive value of $61.4 \%$ and a negative predictive value of $83.3 \%$, with an accuracy of $64 \%$. Conclusion: Image of CESM effectively evaluates hypedense lesions, clearly showing the mass nature, less omission of lesions, thus valuable in diagnosing breast cancer with subjects with dense mammary glands.

Keywords: Breast tumor, contrast enhanced spectral mammography.

\section{I. ĐĂT VẤN ĐỀ}

CESM (Contrast-enhanced spectral mammography) Là một phương pháp chụp $X$ quang tuyến vú đặc biệt, thường được chỉ định trên những bệnh nhân có hình ảnh vú trên phim 2D không kết luận được hoặc nghi ngờ ác tính. CESM sử dụng chất cản quang có i-ốt để phát hiện những vùng tăng tưới máu trong vú, thường là các khối ung thư vú có nguồn cấp máu nhiều hơn tổ chức tuyến vú bình thường $[1,2]$. Với chụp XQ 2 D tuyến vú thông thường dể chẩn đoán đối với những bệnh nhân tuyến vú mõ (typ $A, B)$, với những bệnh nhân tuyến vú đặc (typ C, D) nhu mô tuyến đậm đặc, che lấp các tổn thương khối tăng đậm độ, hạn chế đánh giá tính chất khối (bờ viền, co kéo...) dẫn đến bỏ sót và đánh giá thiếu tính chất tổn thương, và đây cũng là hạn chế rất hay gặp trong sàng lọc ung thư vú ở những tộc người châu Á. Điều quan trọng nhất, với Xquang tuyến vú $2 D$ thông thường không đánh giá được tính chất tăng sinh mạch của khối u là một trong những đăc tính cơ bản và quan trọng trong chẩn đoán phân biệt khối u lành tính hay ác tính. Trong một nghiên cưu hôi cứu được công bố gân đây trên tạp chí Radiology (2019), Sung và CS đã đánh giá CESM như một phương pháp thay thế cho chụp nhũ ảnh tiêu chuẩn để tâm soát ung thư vú [3]. Tại Việt Nam hiện nay chưa có nhiều nghiên cưu về vấn đề này, vì vậy chúng tôi thực hiện nghiên cứu với 
mục tiêu: Đánh giá giá trị chẩn đoán ung thư vú của phương pháp chup X quang CESM so với kết quả mô bệnh học.

\section{II. ĐỐI TƯƠNG VÀ PHƯƠNG PHÁP NGHIÊN CứU}

2.1. Đối tượng nghiên cứu. Các trường hợp phụ nữ mọi lứa tuổi đến khám tại bệnh viện TƯQĐ 108, trong thời gian từ tháng 04/2017 12/2020, có tổn thương vú (sờ thây được hoặc không sờ thấy), có chỉ định chụp XQ tuyến vú có tiêm thuốc cản quang.

\subsection{Phương pháp nghiên cứu}

Loại hình nghiên cứu: Nghiên cứu mô tả cắt ngang, hồi cứu.

\section{KẾT QUẢ NGHIÊN CỨU}

Bảng 1. Phân bố bệnh nhân theo nhóm tuổi

\begin{tabular}{|c|c|c|c|c|c|c|c|}
\hline \multirow{2}{*}{ Nhóm tuối } & \multicolumn{2}{c|}{ Lành GPB } & \multicolumn{2}{c|}{ Ac tính } & \multicolumn{2}{c|}{ Tống } & \multirow{2}{*}{ p } \\
\cline { 2 - 7 } & $\mathbf{n}$ & $\mathbf{\%}$ & $\mathbf{n}$ & $\mathbf{\%}$ & $\mathbf{n}$ & $\mathbf{\%}$ & \\
\hline$<30$ tuối & 1 & 4,55 & 0 & 0 & 1 & 2 & \\
\hline $30-44$ tuối & 11 & 50 & 5 & 17,85 & 16 & 32 & $>05$ \\
\hline $45-60$ tuối & 7 & 31,82 & 16 & 57,14 & 23 & 46 & \\
\hline$>60$ tuối & 3 & 13,64 & 7 & 25 & 10 & 20 & \\
\hline Tống & 22 & 44 & 28 & 56 & $49,86 \pm 12,09$ & \\
\hline
\end{tabular}

Nhân xét: Nhóm tuối hay gặp nhất là từ 45-60 tuối chiếm 46\%, nhóm dưới 30 tuối chỉ có 1 BN. Độ tuối trung bình của bệnh nhân là 49,86 $\pm 12,06$. Nhóm có kết quả giải phẫu bệnh ác tính lớn nhất là nhóm 45-60 tuổi, chiếm 57,14\%.

Bảng 2. Giá trị chẩn đoán dựa trên hinh dang đa thùy trên XQ CESM

\begin{tabular}{|c|c|c|c|}
\hline Đa thùy $\mathrm{MBH}$ & Ác tính & $\begin{array}{l}\text { Lành } \\
\text { tính }\end{array}$ & Tổng \\
\hline Có & 20 & 7 & 27 \\
\hline Không & 8 & 15 & 23 \\
\hline Tống số & 28 & 22 & 50 \\
\hline $\begin{array}{r}\mathrm{Sn}=71,4 \%, \mathrm{Sp} \\
=6\end{array}$ & $\begin{array}{l}68,2 \%, \\
2 \%, \text { Acc }\end{array}$ & $\begin{array}{l}V=74 \\
50 \%\end{array}$ & $\%, \mathrm{NPV}$ \\
\hline
\end{tabular}

Nhân xét: Hình ảnh hình dạng khối u đa thùy trên XQ CESM có độ nhạy $71,4 \%$, độ đặc hiệu $68,2 \%$, giá trị dự báo dương tính $74,1 \%$ và giá tri dự báo âm tính $65,2 \%$, đô chính xác $60 \%$.

Bảng 3. Giá trị chẩn đoán dựa trên đường bờ không rô nét trên XQ CESM

\begin{tabular}{|c|c|c|c|}
\hline $\begin{array}{c}\text { MBH } \\
\text { Không rồ nét }\end{array}$ & $\begin{array}{c}\text { Ác } \\
\text { tính }\end{array}$ & $\begin{array}{l}\text { Lành } \\
\text { tính }\end{array}$ & Tổng \\
\hline Có & 15 & 5 & 20 \\
\hline Không & 13 & 17 & 30 \\
\hline Tổng số & 28 & 22 & 50 \\
\hline
\end{tabular}

Nhân xét: Hình ảnh đường bờ không rõ nét trên XQ CESM có độ nhạy 53,6\%, độ đặc hiệu $77,3 \%$, giá trị dự báo dương tính $75 \%$ và giá trị dự báo âm tính $56,7 \%$, độ chính xác $64 \%$.

Bảng 4. Giá trị chẩn đoán dựa trên hình ảnh vôi hóa trên XQ CESM
Tiêu chuẩn lựa chọn. Tất cả phụ nữ đến khám, phát hiện tổn thương ở vú, được phân loại BI-RADS 3,4,5 trên chụp XQ tuyến vú $2 \mathrm{D}$ có chỉ đinh chup CESM, sau đó được sinh thiết tổn thương, có kết quả xét nghiệm mô bệnh học, đồng ý tham gia nhóm nghiên cứu.

Tiêu chuẩn loại trừ. Bệnh nhân không có kết quả xét nghiệm mô bệnh học, không có đầy

Nội dung nghiên cứu: Tính giá trị chẩn đoán của các đặc điểm khối u vú dựa trên hình dang, đường bờ, tính chất vôi hóa, xâm lấn, đặc điểm ngấm thuốc, hạch trên XQ CESM đủ hồ sơ bênh án.

\begin{tabular}{|c|c|c|c|}
\hline Vôi hóa MBH & $\begin{array}{l}\text { Ac } \\
\text { tính }\end{array}$ & $\begin{array}{l}\text { Lành } \\
\text { tính }\end{array}$ & Tổng \\
\hline Có & 15 & 9 & 24 \\
\hline Không & 13 & 13 & 26 \\
\hline Tống số & 28 & 22 & 50 \\
\hline
\end{tabular}

Nhận xét: Hình ảnh vôi hóa trên XQ CESM có độ nhạy 53,6\%, độ đặc hiệu 59,1\%, giá trị dự báo dương tính $62,5 \%$ và giá trị dự báo âm tính $50 \%$, độ chính xác $56 \%$.

Báng 5. Giá trị chẩn đoán dựa trên tình trạng hạch trên XQ CESM

\begin{tabular}{|c|c|c|c|}
\hline Hạch MBH & Ác tính & $\begin{array}{c}\text { Lành } \\
\text { tính }\end{array}$ & Tổng \\
\hline Có & 13 & 7 & 20 \\
\hline Không & 15 & 15 & 30 \\
\hline Tống số & $\mathbf{2 8}$ & $\mathbf{2 2}$ & $\mathbf{5 0}$ \\
\hline Sn = 46,4\%, Sp =68,2\%, PPV = 65\%, NPV = \\
$50 \%$, ACc = 56\% \\
\hline \multicolumn{4}{|c|}{} \\
\hline
\end{tabular}

Nhận xét: Tình trang hach trên XQ CESM có độ nhạy $46,4 \%$, độ đặc hiệu $68,2 \%$, giá trị dự báo dương tính $65 \%$ và giá trị dự báo âm tính $50 \%$, độ chính xác $56 \%$.

Bảng 6. Giá trị chẩn đoán dựa trên tình trạng xâm lấn trên XQ CESM

\begin{tabular}{|c|c|c|c|}
\hline Xâm lấn MBH & $\begin{array}{c}\text { Ac } \\
\text { tính }\end{array}$ & $\begin{array}{c}\text { Lành } \\
\text { tính }\end{array}$ & Tổng \\
\hline Có & 12 & 1 & 13 \\
\hline
\end{tabular}




\begin{tabular}{|c|c|c|c|}
\hline Không & 16 & 21 & 37 \\
\hline Tống số & $\mathbf{2 8}$ & $\mathbf{2 2}$ & $\mathbf{5 0}$ \\
\hline $\begin{array}{c}\text { Sn }=42,9 \%, \mathrm{Sp}=95,5 \%, \mathrm{PPV}=92,3 \%, \text { NPV } \\
=56,8 \%, \text { Acc }=66 \%\end{array}$ \\
\hline
\end{tabular}

Nhân xét: Hình ảnh xâm lấn trên XQ CESM có độđặc hiệu cao 95,5\%.

Bảng 7. Giá trị chẩn đoán dựa trên tình trạng ngấm thuốc trên XQ CESM

\begin{tabular}{|c|c|c|c|}
\hline Ngấm thuớc & Ác tính & $\begin{array}{l}\text { Lành } \\
\text { tính }\end{array}$ & Tổng \\
\hline Có & 25 & 2 & 27 \\
\hline Không & 3 & 20 & 23 \\
\hline Tống số & 28 & 22 & 50 \\
\hline
\end{tabular}

Nhận xét: Hình ảnh ngấm thuốc trên $\mathrm{XQ}$ CESM có độ nhạy và độ đặc hiệu cao 89,3\%, độ đặc hiêu $90,9 \%$.

Bảng 8. Giá trị chẩn đoán dựa trên phân loại $B I-R A D S$ trên XQ CESM với BI-RADS $\geq 4$

\begin{tabular}{|c|c|c|c|}
\hline Birads $\geq 4$ & Ác tính & $\begin{array}{l}\text { Lành } \\
\text { tính }\end{array}$ & Tổng \\
\hline Có & 27 & 17 & 44 \\
\hline Không & 1 & 5 & 6 \\
\hline Tống số & 28 & 22 & 50 \\
\hline
\end{tabular}

Nhận xét: Phân loại BIRADS $\geq 4$ trên XQ CESM có độ nhạy cao 96,4\%.

\section{BÀN LUÂN}

Theo kết quả chúng tôi thu được, hình ảnh uđa thùy trên XQ CESM có độ nhạy $71,4 \%$, độ đặc hiệu $68,2 \%$, giá trị dự báo dương tính $74,1 \%$ và giá trị dự báo âm tính $65,2 \%$, đô chính xác $60 \%$. Theo tác giả Nguyễn Văn Thắng, tổn thương có hình đa diện của các tổn thương UTV trên cả $X Q$ và siêu âm đều cao $(80,4 \%$ và 78,3\%), nhưng độ đặc hiệu không cao, trên XQ $71,43 \%$ và trên SA $50 \%$ [5]. Độ đặc hiệu của dấu hiệu này trong nghiên cứu của chúng tôi còn thấp, điều này được giải thích do đa phần $\mathrm{BN}$ của chúng tôi có mô vú thuộc týp vú đặc, do đó sự chồng tuyến đã phần nào gây khó khăn cho việc nhận định hình thái tổn thương.

Hình ảnh đường bờ không rõ nét trên $X Q$ CESM có độ nhạy 53,6\%, độ đặc hiệu 77,3. Theo tác giả Constantini trong nghiên cứu năm 2006 cho thấy dấu hiệu tổn thương có đường bờ nham nhở hình sao có giá trị trong chẩn đoán UTV, độ nhạy 90,6\%, độ đặc hiệu 87,8\% [6]. Hình ảnh vôi hóa trên XQ CESM có độ nhạy $53,6 \%$, độ đặc hiệu 59,1\%, giá trị dự báo dương tính $62,5 \%$ và giá trị dự báo âm tính $50 \%$, độ chính xác $56 \%$. Cũng theo tác giả Nguyễn Văn
Thắng, dấu hiệu vôi hóa trên XQ cho độ nhạy $34,78 \%$, độ đặc hiệu $75 \%$. Trên siêu âm, độ nhạy và độ đặc hệu lần lượt là $30,43 \%$ và $89,29 \%[5]$.

Với hình ảnh $X Q$ và siêu âm bình thường không có bệnh lý đôi khi chúng ta vẫn quan sát thấy hạch nách và đó là hình ảnh hạch nách bình thường. Trên siêu âm hạch bình thường là những cấu trúc hình bầu dục, hình chữ $C$ giảm âm ở ngoại vi (vỏ hạch) và tăng âm ở trung tâm (mõ rốn hạch), vỏ hạch thường dày $<3 \mathrm{~mm}$ và đều. Trên $X Q$ là những cấu trúc hình tròn hay hình bầu dục, kích thước thường dưới $1 \mathrm{~cm}$, đậm độ cản quang mức độ trung bình, vùng trung tầm thấu quang hơn so với ngoại vi đó là biểu hiện bình thường của cấu trúc mõ̃ rốn hạch. Kết quả nghiên cứu của chúng tôi, tình trạng hạch trên XQ CESM có độ nhạy 46,4\%, độ đặc hiệu $68,2 \%$, giá trị dự báo dương tính $65 \%$ và giá trị dự báo âm tính $50 \%$, độ chính xác $56 \%$.

Hình ảnh xâm lấn trên XQ CESM có độ nhạy 42,9\%, độ đặc hiệu 95,5\%, giá trị dự báo dương tính $92,3 \%$ và giá trị dự báo âm tính $56,8 \%$, độ chính xác $66 \%$. Constatini (2006), nghiên cứu cho thấy dấu hiệu xâm lấn trên siêu âm cho giá trị dự báo dương tính $86 \%$, tác giả cũng cho thấy rằng dấu hiệu này thường đi kèm theo các hình ảnh tổn thương khối u có hình đa diện, khó định dạng, tổn thương có bờ nham nhở không đều, hình sao. Đặc biệt hơn nữa nếu tổn thương có chỉ số $D / W>1$. Dấu hiệu có biểu hiên xâm lấn là hình ảnh dày lên của cấu trúc da và mô dưới da, tác giả cũng nhấn mạnh rằng đây là dấu hiệu chính để phân biệt một tổn thương lành tính hay ác tính [6]. Theo Nguyễn Văn Thắng, giá trị chẩn đoán UTV của dấu hiệu xâm lấn trên XQ là $\mathrm{Se}=$ $8,7 \%, \mathrm{Sp}=100 \%$, PPV $=100 \%$ [5].

Hình ảnh ngấm thuốc trên XQ CESM có độ nhạy $89,3 \%$, độ đặc hiệu $90,9 \%$, giá trị dự báo dương tính $92,6 \%$ và giá trị dự báo âm tính $87 \%$, độ chính xác $90 \%$.Phân loại BIRADS $\geq 4$ trên XQ CESM có độ cao 96,4\%.Nghiên cứu của Berg W.A. và CS (2004) cho thấy rằng $X Q$ có độ nhay $100 \%$ trong chẩn đoán UTV ở nhóm có tuyến vú mõ hóa cao, 45\% ở nhóm mô vú đậm đặc [7]. Theo Nguyễn Văn Thắng độ nhạy trong chẩn đoán UTV của XQ là 89,13\% [5].

So với một số nghiên cứu trước độ đặc hiêu có phần thấp hơn, điều này có thể do phần lớn các đối tượng nghiên cứu của chúng tôi tới viện vì tự phát hiện thấy tổn thương khối tại vú, 28 khối u ác tính và 22 khối u lành. Chính do phần lớn $\mathrm{BN}$ đến đều thấy có bất thường tại vú nên khi chụp XQ chúng tôi gặp rất nhiêu các hình 
ảnh bất thường cân phải phân biệt
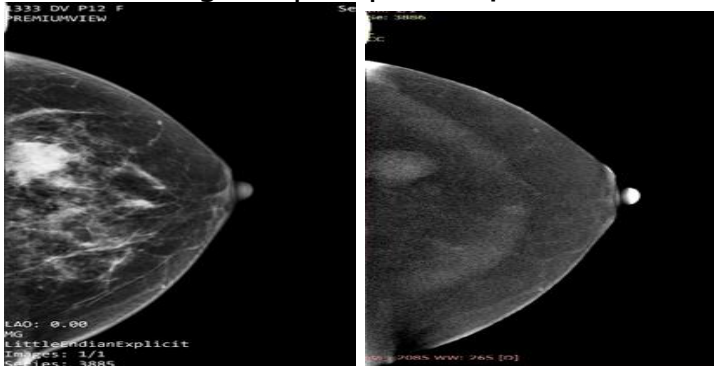

Hình ảnh minh họa khối u vú phải với tư thễ chụp từ trên xuống, trước và sau tiêm thuốc cản quang, xuất hiện nốt ngấm thuốc nhỏ hơn phía trước, ngay sau núm vú. Kết quả mô bệnh học là ung thư biểu mô ống xâm nhập.

\section{KẾT LUÂ̂N}

Hình ảnh Chụp XQ tuyến vú phổ hai mức năng lượng CESM đánh giá hiệu quả những tổn thương tăng đậm độ, thể hiện rõ ràng tính chất khối, ít bỏ sót tổn thương, do đó có giá trị trong việc chẩn đoán ung thư vú với các đối tượng có tuyến vú đậm đặc.

TÀl LIỆ THAM KHẢO
1. Nada A.M.A.M., Hamdi R., Shokry A. (2017). Dual energy contrast enhanced soft tissue digital mammography versus ultrasound elastography in the evaluation of breast masses. The Egyptian Journal of Radiology and Nuclear Medicine, 48(4), 1179-1186.

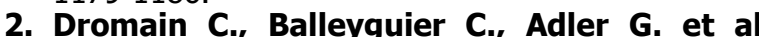
(2009). Contrast-enhanced digital mammography. Eur J Radiol, 69(1), 34-42.

3. Sung J.S., Lebron L., Keating D. et al (2019). Performance of Dual-Energy Contrast-enhanced Digital Mammography for Screening Women at Increased Risk of Breast Cancer. 293(1), 81-88.

4. Spak D.A., Plaxco J.S., Santiago L. et al (2017). BI-RADS((R)) fifth edition: A summary of changes. Diagn Interv Imaging, 98(3), 179-190.

5. Nguyến Văn Thắng (2013), Nghiên cứu giá trị chẩn đoán ung thư vú của chup $X$ quang kêt hợp siêu âm tuyến vú, Luận văn thạc sĩ y học, Đại học Y Hà Nội.

6. Costantini M., Belli P., Lombardi R. et al (2006). Characterization of solid breast masses: use of the sonographic breast imaging reporting and data system lexicon. J Ultrasound Med, 25(5), 649-659; quiz 661.

7. Berg W.A., Gutierrez L., NessAiver M.S. et al (2004). Diagnostic accuracy of mammography, clinical examination, US, and MR imaging in preoperative assessment of breast cancer. Radiology, 233(3), 830-849.

\section{PHÂN TÍCH CHI PHÍ ĐIỀU TRI BÊNH PHỔI TẮC NGHẼN MAN TÍNH THEO QUAN ĐIỂM NGƯỜI CHI TRẢ TẠI BỆNH VIỆN QUẦN 11}

\section{Dương Thái Bình ${ }^{1}$, Đặng Thị Ngọc² ${ }^{2}$ Nguyễn Thị Xuân Liễu ${ }^{3}$, Trương Thị Thu Hoàn ${ }^{2}$, Nguyễn Thị Thu Thuỷ ${ }^{1}$}

\section{TÓM TẮT}

Mở đâu: Bệnh phổi tắc nghẽn mạn tính (COPD Chronic Obstructive Pulmonary Disease) hiện nay đang trở thành một trong những vấn đề bệnh lý nghiêm trong gây ra bênh tât và tử vong hàng đầu trên thế giới cũng như tại Việt Nam. Trên thế giới đã có những nghiên cứu nhằm phân tích chi phí trong điều trị COPD và đây cũng là 1 trong những bước quan trọng nhằm cung cấp cái nhìn tổng quan về gánh năng kinh tế của bênh tại Việt Nam. Mục tiêu: Phân tích chi phí điều trì bểnh phổi tắc nghẽn man tính theo quan điểm ngườ chi trả tại bệnh viện Quận 11. Phương pháp nghiên cứu: Mổ tả cắt ngang dựa trên dữ liêu thu thập từ hồi cứu hồ sơ bệnh án và phỏng vấn toàn bộ người bệnh

${ }^{1}$ Đại học Y Dược Thành phố Hồ Chi Minh

²Bênh viện Quận 11, Thành phố Hồ Chí Minh

${ }^{3}$ Trường Đại học Nguyễn Tất Thành

Chiu trách nhiểm chính: Nguyễn Thị Thu Thuỷ

Email: nguyenthuthuy@ump.edu.vn

Ngày nhận bài: 14.6.2021

Ngày phản biện khoa học: 9.8.2021

Ngày duyệt bài: 18.8.2021 phổi tắc nghẽn mạn tính đến khám và điều trị tại Bệnh viện Quận 11 trong thời gian từ tháng 2 đến hết tháng 5 năm 2021 thỏa tiêu chí lựa chon và loai trừ. Nghiên cứu được thực hiên theo quan điểm người chi trả bao gồm cơ quan chi trả BHYT và người bệnh vì vậy các chi phí trực tiếp (y tế, ngoài y tế) và gián tiếp được đánh giá. Kết quả: Chi phí mỗi tháng điều trị tăng dần theo mức độ nặng của bênh với giá trị lần lướt là 78.478,22; 214.303,02; 267.937,06; 713.248,11 đồng cho các giai đoan từ GOLD A đến GOLD D. Như vây chi phí điều trị giai đoạn GOLD D gấp 9,09 lần giai đoạn GOLD A. Về cấu trúc, chi phí trực tiếp y tế chiếm tỷ lê cao nhất ở cả 4 giai đoan bênh, tiếp theo là chi phí gián tiếp và thấp nhất là chi phí trực tiếp ngoài y tế. Kết luân: Nghiên cứu ghi nhân tổng chi phí 1 tháng điều trị của người bệnh COPD tăng dần theo mức độ nặng của bệnh và chi phí trực tiếp y tế chiếm tỷ lề cao nhất.

Tư khoá: bênh phổi tắc nghẽn mạn tính, chi phí điều trị, bệnh viện quận 11

\section{SUMMARY \\ ANALYZE TREATMENT COST OF CHRONIC OBSTRUCTIVE PULMONARY DISEASE}

